\title{
IMPLEMENTASI IOT PADA SMART AIR CONDITIONING DENGAN METODE FUZZY LOGIC
}

\author{
Muhammad Yudi Abdul Syawari ${ }^{1}$,Ridwan Yusuf ${ }^{2}$,Budi Sutomo ${ }^{3}$ \\ ${ }^{1}$ Muhammad Yudi Abdul Syawari, STMIK Dharma Wacana muhammadyudi510@gmail.com \\ ${ }^{2}$ Ridwan Yusuf, STMIK Dharma Wacana kinglotto@yahoo.com \\ ${ }^{3}$ Budi Sutomo, STMIK Dharma Wacana budi.atmel@ gmail.com \\ ${ }^{1}$ Program Studi Teknik Informatika, STMIK Dharma Wacana \\ ${ }^{2}$ Jalan Kenangan No.3 Mulyojati Kota Metro, Lampung \\ Email : muhammadyudi510gmail@gmail.com
}

\begin{abstract}
ABSTRAK
Tidak dapat dipungkiri bahwa permintaan masyarakat akan peralatan pendingin ruangan atau yang lebih dikenal dengan AC (air conditioning) semakin meningkat, terutama di industri, perkantoran, bahkan area kecil seperti rumah.Logika Fuzzy merupakan suatu logika yang memiliki nilai kekaburan atau kesamaran (fuzzyness) antara benar atau salah. Dengan menggunakan Inferensi Fuzzy sebagai alat bantu hitung yang akan dikeluarkan oleh AC nanti nya bisa di dapatkan nilai output suhu tersebut pada ruang tertutup berdasarkan input nilai suhu ruangan pada saat itu dan jumlah sensor pir yang terdeteksi,sebagai pengontrol AC tujuan penelitian ini menerapkan fuzyy logic pada proses penentuan nilai suhu yang akan di keluarkan yang nanti nya dapat diterapkan pada IOT. Internet of things atau IOT adalah suatu konsep atau program dimana benda dapat terkoneksi ke jaringan internet sehingga memungkinkan kita untuk mengontrol atau memonitoring benda tersebut dari jarak jauh.
\end{abstract}

Kata Kunci: Pengontrol AC IOT, Pengontrol AC otomatis, Fuzzy Logic

\section{PENDAHULUAN}

\subsection{Latar Belakang Masalah}

Teori himpunan fuzzy atau himpunan implisit pertama kali dikemukakan oleh Lotfi Zadeh dalam makalah yang disebut "himpunan fuzzy" sekitar tahun 1965. Sejak itu, sejak pertengahan 1970-an, peneliti Jepang berhasil menerapkan teori ini pada masalah teknis. Logika fuzzy merupakan penyempurnaan dari logika Boolean, logika Boolean berkaitan dengan konsep bagian dari nilai kebenaran. Ketika logika klasik dinyatakan, semuanya dapat didefinisikan dalam istilah biner. Logika fuzzy memiliki banyak aplikasi dalam menangani masalah sehari-hari. Salah satu masalah yang dapat diatasi dengan penerapan logika fuzzy adalah pengaturan otomatis beberapa alat elektronik, seperti mesin cuci, penghancur bumbu, alat pemanas listrik, dll. Saat ini penggunaan logika fuzzy juga telah banyak digunakan di IOT atau (Internet of Things). Internet of Things adalah konsep di mana objek tertentu memiliki kemampuan untuk mengirimkan data melalui jaringan tanpa memerlukan interaksi manusia-ke-manusia atau manusia-komputer. Contoh penerapan logika fuzzy pada IOT adalah sebagai pengendalian arus tenaga listrik,pengontrol ketinggian air dan monitoring peralatan listrik,penerapan logika Fuzzy pada IOT ini akan menghasilkan Teknologi smart yang dapat membantu kebutuhan manusia menjadi lebih mudah. Penggunaan Teknologi Smart juga dapat diaplikasikan ke dalam Air conditioning (AC). Pada AC Berfungsi Sebagai Penyejuk Udara yang diinginkan. Saat ini perlakuan penggunaan AC 
masih banyak yang tidak sesuai dengan peraturan mentri Energi dan Sumber Daya Mineral Republik Indonesia,tahun 2012 nomor 13, Pasal 4, yaitu untuk gedung nasional dan gedung BUMN, BUMD dan BHMN, apabila menggunakan AC

\subsection{Metode Fuzzy Logic (Tsukamoto)}

Logika fuzzy merupakan salah satu cara untuk menemukan solusi dari permasalahan yang di anggap samar. Dalam solusinya, logika fuzzy menggunakan bahasa seperti "agak tinggi", "agak tinggi", "agak panas", "panas", dll. Dalam studi ini, kami menggunakan metode fuzzy Tsukamoto untuk terlebih dahulu menentukan fungsi keanggotaan, kemudian menentukan aturan, kemudian mengelompokkan kategori ke dalam masingmasing kelompok sesuai dengan aturan yang diterapkan. Metode Tsukamoto yang digunakan adalah metode "center average defuzzer".

Grafik Keanggotaan Pir

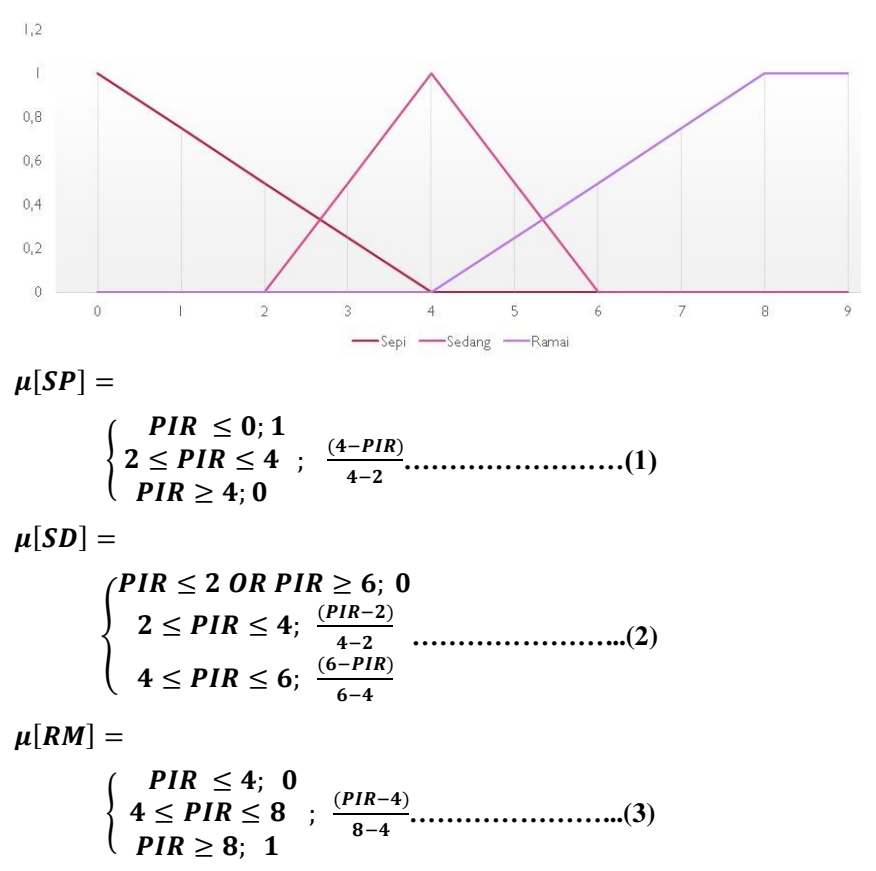

Grafik keangotaan sensor DHT

Tabel Rule FAM dilakukan dengan cara, Mematikan AC pada saat tidak digunakan dan mengatur suhu ruangan sesuai dengan banyak nya orang di dalam ruangan.

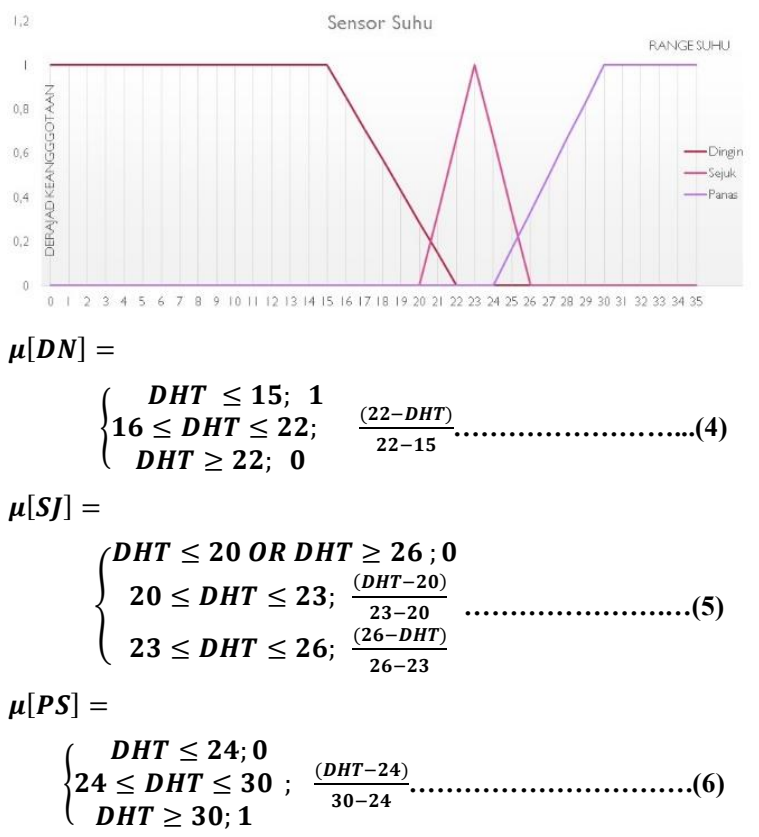

Grafik keanggotaan REM

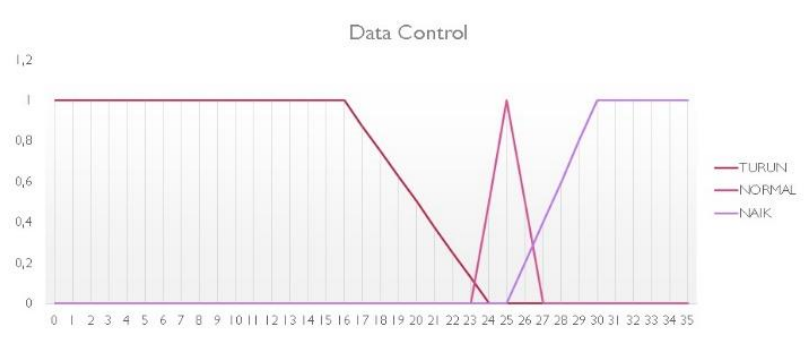

$\mu[T R]=$

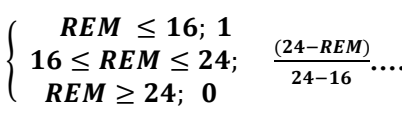

$\mu[N R]=$

$$
\left\{\begin{aligned}
R E M & \leq 23 \text { OR REM } \geq 27 ; \quad 0 \\
23 & \leq R E M \leq 25 ; \\
25 & \leq R E M \leq 27 ; \frac{(27-R E M-23)}{27-25}
\end{aligned} \cdots\right.
$$

$\mu[N K]=$

$$
\left\{\begin{array}{c}
R E M \leq 25 ; 0 \\
25 \leq R E M \leq 30 ; \quad \frac{(R E M-25)}{30-25} . . \\
R E M \geq 30 ; 1
\end{array}\right.
$$

\begin{tabular}{|l|l|l|l|}
\hline $\begin{array}{l}\text { Input suhu } \\
\text { Input jumlah sensor }\end{array}$ & Dingin (DI) & Sejuk (SE) & Hangat (HT) \\
\hline Sepi (SP) & NK & NR & NR \\
\hline Sedang (SD) & NR & NR & TR \\
\hline Ramai (RM) & TR & TR & TR \\
\hline
\end{tabular}


Sembilan aturan fuzzy yang dibentuk dari table

Defuzzyfikasi FAM

\begin{tabular}{|c|l|}
\hline Rule & \multicolumn{1}{|c|}{ Keterangan } \\
\hline 1 & IF PIR $=$ SP AND DHT $=$ DI THEN REM $=$ NK \\
\hline 2 & IF PIR $=$ SP AND DHT $=$ SE THEN REM $=$ NR \\
\hline 3 & IF PIR = SP AND DHT $=$ HT THEN REM $=$ NR \\
\hline 4 & IF PIR $=$ SD AND DHT $=$ DI THEN REM $=$ NR \\
\hline 5 & IF PIR $=$ SD AND DHT $=$ SE THEN REM $=$ NR \\
\hline 6 & IF PIR $=$ SD AND DHT $=$ HT THEN REM $=$ TR \\
\hline 7 & IF PIR $=$ RM AND DHT $=$ DI THEN REM $=$ TR \\
\hline 8 & IF PIR $=$ RM AND DHT $=$ SE THEN REM $=$ TR \\
\hline 9 & IF PIR $=$ RM AND DHT $=$ HT THEN REM $=$ TR \\
\hline
\end{tabular}

\section{2.(internet of things)}

Internet of Things (IoT) dirancang untuk mengubungkan jaringan benda ke jaringan internet, memungkinkan kita untuk dapat menghubungkan mesin, perangkat, dan objek fisik melalui jaringan internet dan sensor untuk mendapatkan data dan mengelola kinerjanya sendiri ini memungkinkan mesin untuk bekerja secara otomatis. Ide dari IOT adalah semua objek di dunia nyata dapat menggunakan jaringan internet sebagai penghubung untuk berkomunikasi satu sama lain sebagai bagian dari sistem yang terintegrasi.

Ide asli IOT pertama kali dikemukakan oleh Kevin Ashton dalam pidatonya tahun 1999. Sekarang, banyak perusahaan besar mulai menjelajahi Internet of Things, termasuk Intel, Microsoft, Oracle, dan banyak perusahaan lainnya. Banyak orang memperkirakan bahwa dampak Internet of Things akan menjadi "next big thing" di dunia teknologi informasi, karena Internet of Things memberikan banyak potensi yang dapat digali. Sebagai contoh contoh sederhana yang menggambarkan manfaat dan implementasi dari Internet of Things, yaitu sebuah lemari makanan atau tempat penyimpanan ES yang dapat memberikan notifikasi ke pem. Dengan menyebutkan tiga elemen utama arsitektur IoT, konsep IoT sebenarnya sangat sederhana, yaitu: item fisik yang dilengkapi modul IoT, perangkat yang terhubung dengan internet (seperti modem dan router nirkabel cepat di rumah), dan data cloud. Lokasi ditempatkan di lokasi pusat aplikasi penyimpanan bersama dengan database.

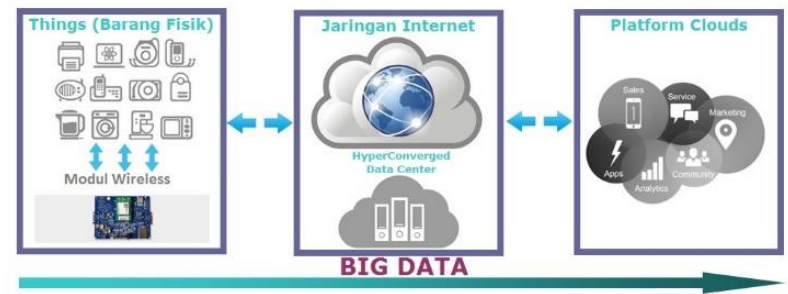

Prinsip kerja IoT menghubungkan benda-benda di dunia nyata melalui jaringan internet sehingga dapat di control atau dimonitoring dari jarak jauh. Pada masa awal penerapan konsep IoT, adalah pengembangan alat pembaca barcode atau (RFID). Dalam perkembangannya, objek dapat diberikan pengenal berupa alamat IP, dan jaringan internet dapat digunakan untuk berkomunikasi dengan objek lain dengan pengenal alamat IP. Cara kerja Internet of Things adalah menggunakan pemrograman variabel independen, di mana setiap perintah variabel independen akan berinteraksi antara mesin lain, mesin ini secara otomatis terhubung tanpa intervensi manual dan tidak terpengaruh oleh jarak apapun. Internet adalah penghubung antara interaksi dua mesin, dan manusia hanya bertindak sebagai pengawas dan pengawas operasi alat.

Berdasarkan uraian di atas, maka peneliti bermaksud untuk melakukan penelitian untuk merancang prototype pengontrol AC dari jarak jauh menggunakan jaringan internet melalui smartphone android, sehingga kondisi suhu ruangan dan hidup atau mati nya AC tersebut dapat di control dari jarak jauh melalui smartphone.

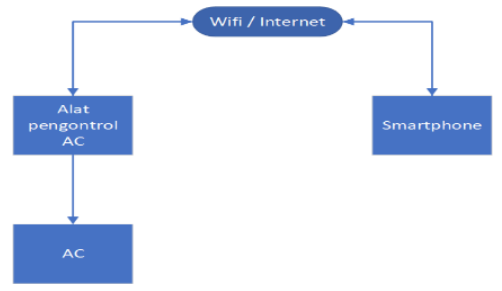

Pada gambar di atas menunjukan blok diagram IOT pengontrol AC dari jarak jauh dimana alat pengontrol AC dapat mengirimkan code remot ke $\mathrm{AC}$ dan juga dapat terkoneksi ke jaringan internet untuk terhubung ke smartphone android

\subsection{HASIL DAN PEMBAHASAN}

Pada tahap hasil dan pembahasan akan di lakukan pengujian. Berapa Data yang harus dikirim oleh remote jika pada saat itu suhu ruangan adalah 25 drajat dan sensor pir yang terdeteksi adalah 5 berapakah output suhu nya..? 
(DN) $25=0$

(SJ) $25=\frac{26-25}{26-23}$

$$
=\frac{1}{3}=0,33
$$

(HG) $25=\frac{25-24}{30-24}$

$$
=\frac{1}{6}=0,16
$$

\section{Drajat keanggotaan PIR}

(SP) $5=0$

(SD) $5=\frac{6-5}{6-4}$

$$
\begin{aligned}
& =\frac{1}{2}=0,5 \\
(\mathrm{RM}) 5= & \frac{5-4}{8-4} \\
= & \frac{1}{4}=0,25
\end{aligned}
$$

\section{Mesin Infrensi}

R1. Sepi dan dingin $=$ naik $\left(\begin{array}{ccc}0 ; 0 \quad)=0 \\ \text { a }\end{array}\right.$ Naik $=\frac{R E M-25}{35-25}=0 \quad$ Rem $=(10 \mathrm{x})+25$ $=0+25=25$

R2. Sepi dan sejuk $=$ Normal $\left(\begin{array}{ll}0 ; 0,33 \quad)=0 \\ \text { Not }\end{array}\right.$ Normal $=\frac{R E M-23}{20-23}=0 \quad$ Rem $=(2 \mathrm{x} 0)+23=20$ Normal $=\frac{27-R E M}{27-25}=0 \quad$ Rem $=27-(2 \times 0)=27$

R3. Sepi dan hangat $=$ Normal $(\quad 0 ; 0,16)=0$ Normal $=\frac{R E M-23}{25-23}=0 \quad$ Rem $=(2 \mathrm{x} 0)+23=23$ Normal $=\frac{27-R E M}{27-25}=0 \quad$ Rem $=27-(2 \times 0)=27$

R4. Sedang dan dingin $=$ Normal $(\quad 0,5 ; 0)=0$ Normal $=\frac{R E M-23}{25-23}=0 \quad \operatorname{Rem}=(2 \times 0)+23=23$ Normal $=\frac{27-R E M}{27-25}=0 \quad$ Rem $=27-(2 \times 0)=27$

R5. Sedang dan sejuk $=$ Normal $(0,5 ; 0,33)=0,33$ Normal $=\frac{R E M-23}{25-23}=0 \quad$ Rem $=(2 \times 0,33)+23=23,66$ Normal $=\frac{27-R E M}{27-25}=0 \quad$ Rem $=27-(2 \times 0,33)=26,34$

R6. Sedang dan hangat $=$ Turun $(0,5 ; 0,16)=0,16$ Turun $=\frac{24-R E M}{24-16}=0,16 \quad$ Rem $=24-(8 \times 0,16) \quad=22,72$

R7. Ramai dan dingin $=$ Turun $(0,25 ; 0)=0$ Turun $=\frac{24-R E M}{24-16}=0 \quad$ Rem $=24-(8 \times 0) \quad=24$ R8. Ramai dan sejuk $=$ Turun $(0,25 ; 0,33)=0,25$ Turun $=\frac{24-R E M}{24-16}=0,25 \quad$ Rem $=24-(8 \times 0,25)=22$
R9. Ramai dan hangat $=$ Turun $(0,25 ; 0,16)=0,16$ Turun $=\frac{24-R E M}{24-16}=0,16 \quad$ Rem $=24-(8 \times 0,16)=22,72$

$(0,33 \times 23,66)+(0,33 \times 26,34)+(0,16+22,72)+(0,25 \times 22)+(0,16 \times 22,72)$ $0,33+0,33+0,16+0,25+0,16$

$$
\frac{29,2704}{1,23}=23,79^{\circ} \mathrm{C}
$$

Tabel Black Box

\begin{tabular}{|l|l|l|l|l|}
\hline No & \multicolumn{1}{|c|}{$\begin{array}{c}\text { Skenario } \\
\text { Pengujian }\end{array}$} & $\begin{array}{c}\text { Hasil yang di } \\
\text { harapkan }\end{array}$ & Hasil Pengujuan & Kesimpulan \\
\hline 1 & $\begin{array}{l}\text { Menyalakan } \\
\text { Alat }\end{array}$ & $\begin{array}{l}\text { System akan } \\
\text { menyala dan akan } \\
\text { tampil tulisan di } \\
\text { LCD No Internet }\end{array}$ & & \\
\hline $\mathbf{2}$ & $\begin{array}{l}\text { Mengkoneksikan } \\
\text { Alat ke jaringan } \\
\text { internet (Wifi) }\end{array}$ & $\begin{array}{l}\text { Akan tampil } \\
\text { Tulisan Connected } \\
\text { dan setelah itu akan } \\
\text { muncul tulisan }\end{array}$ & Berhasil \\
\hline
\end{tabular}

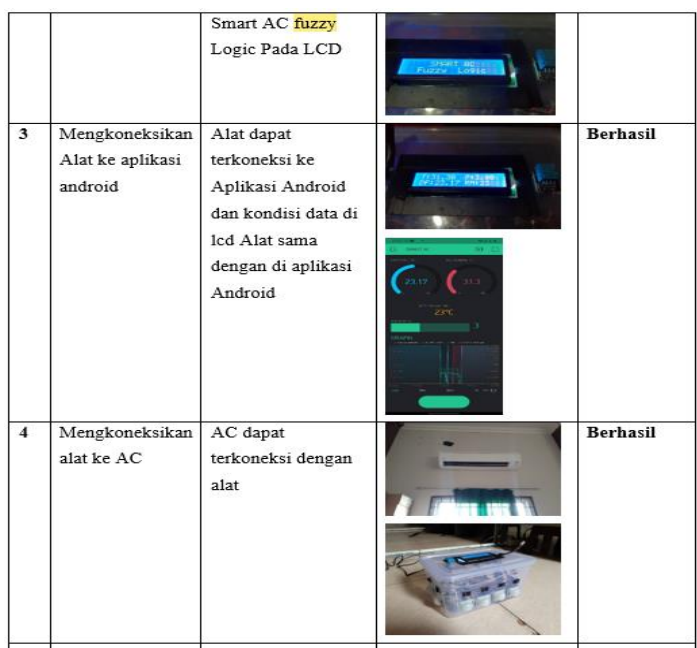

Dengan demikian melihat hasil pengujian data dapat di simpulkan implementasi IOT pada smart air conditioning dengan metode fuzzy logic dapat dikatakan berhasil dimana jika suhu ruangan 25 drajat dan sensor yang terdeteksi ada 5 maka output suhu nya adalah 23.9 drajat Celsius. 


\subsection{Kesimpulan Dan Saran}

\section{A. Kesimpulan}

Berdasarkan hasil pengujian system smart air conditioning dengan metode fuzzy logic Terdapat empat variabel input dan satu variabel output, diantaranya variabel input adalah suhu ruangan dan jumlah sensor PIR yang terdeteksi dan untuk variable output nya adalah suhu. Pada penelitian ini, maka dapat di tarik kesimpulan implementasi IOT pada smart air conditioning dengan metode fuzzy logic mendapatkan hasil yang di harapkan

\section{DAFTAR PUSTAKA}

(Jurnal Teknologi Informasi) Vol.2, N. D. (2018). IMPLEMENTASI LOGIKA FUZZY DALAM MENENTUKAN. Muhammad Dedi Irawan1, 129-137.

Handayani, F. (2019). TREN MASIF INTERNET OF THINGS (IOT) DI PERPUSTAKAAN. IPI (Jurnal IImu Perpustakaan dan Informasi) Vol. 4 No. 2 Tahun 2019, 194-209.

Jurnal IImiah Ilmu Komputer, V. 4. (2018). INTERNET OF THINGS (IOT) SISTEM PENGENDALIAN LAMPU. Yoyon Efendi , 19-26.

(Jurnal Teknologi Informasi) Vol.2, N. D. (2018). IMPLEMENTASI LOGIKA FUZZY DALAM MENENTUKAN. Muhammad Dedi Irawan1, 129-137.

Handayani, F. (2019). TREN MASIF INTERNET OF THINGS (IOT) DI PERPUSTAKAAN. IPI (Jurnal Ilmu Perpustakaan dan Informasi) Vol. 4 No. 2 Tahun 2019, 194-209.

Jurnal IImiah IImu Komputer, V. 4. (2018). INTERNET OF THINGS (IOT) SISTEM PENGENDALIAN LAMPU. Yoyon Efendi, 19-26. dibuktikan pada pengujian perhitungan dengan input suhu ruangan 25 drajat dan 5 sensor pir yang terdeteksi maka output suhu nya adalah 23.9 drajat.

\section{B. Saran}

Diharapkan kedepan nya untuk system ini tidak lagi menggunakan sensor pir sebagai media untuk mendeteksi keberadaan dan jumlah manusia di dalam ruangan,tetapi bisa menggunakan kamera.

(Jurnal Teknologi Informasi) Vol.2, N. D. (2018). IMPLEMENTASI LOGIKA FUZZY DALAM MENENTUKAN. Muhammad Dedi Irawan1, 129-137.

Handayani, F. (2019). TREN MASIF INTERNET OF THINGS (IOT) DI PERPUSTAKAAN. IPI (Jurnal Ilmu Perpustakaan dan Informasi) Vol. 4 No. 2 Tahun 2019, 194-209.

Jurnal IImiah IImu Komputer, V. 4. (2018). INTERNET OF THINGS (IOT) SISTEM PENGENDALIAN LAMPU. Yoyon Efendi, 19-26.

(Jurnal Teknologi Informasi) Vol.2, N. D. (2018). IMPLEMENTASI LOGIKA FUZZY DALAM MENENTUKAN. Muhammad Dedi Irawan1, 129-137.

Handayani, F. (2019). TREN MASIF INTERNET OF THINGS (IOT) DI PERPUSTAKAAN. IPI (Jurnal Ilmu Perpustakaan dan Informasi) Vol. 4 No. 2 Tahun 2019, 194-209.

Jurnal IImiah IImu Komputer, V. 4. (2018). INTERNET OF THINGS (IOT) SISTEM PENGENDALIAN LAMPU. Yoyon Efendi , 19-26.

(Jurnal Teknologi Informasi) Vol.2, N. D. (2018). IMPLEMENTASI LOGIKA FUZZY DALAM 
MENENTUKAN. Muhammad Dedi

Irawan1, 129-137.

Handayani, F. (2019). TREN MASIF INTERNET OF THINGS (IOT) DI PERPUSTAKAAN. IPI (Jurnal IImu Perpustakaan dan Informasi) Vol. 4 No. 2 Tahun 2019, 194-209.
Jurnal IImiah Ilmu Komputer, V. 4. (2018). INTERNET OF THINGS (IOT) SISTEM PENGENDALIAN LAMPU. Yoyon Efendi, 19-26. 